\title{
NUEVAS PERSPECTIVAS EN PSICOLOGÍA COMUNITARIA Y PSICOLOGÍA SOCIAL CRÍTICA
}

\section{NEW PERSPECTIVES IN COMMUNITY PSYCHOLOGY AND CRITICAL SOCIAL PSYCHOLOGY Maritza Montero \\ Universidad Central de Venezuela (UCV), Venezuela}

Palabras clave: psicología comunitaria, ideas principales, psicología social crítica. Keywords: community psychology, main ideas, critical social psychology.

En la Psicología Comunitaria partimos de dos ideas básicas, que son compartidas hasta donde se, en todos los programas de Psicología Comunitaria que conozco, que he visitado o sobre los cuales he leído.

La primera es la idea de complejidad. El trabajo comunitario es muy complejo, para comprender esa complejidad, debemos ir a sus orígenes: La Psicología Comunitaria parte de unos orígenes en los cuales, en el caso del norte del Continente, de los Estados Unidos, específicamente, eran cuatro: la psicología clínica, la psicología organizacional, la psicología educativa y el origen en la Psicología social. Eso ocurrió además, formalmente, en una reunión en Swampscott (Massachussett) en 1965.

En el caso nuestro, en América Latina, donde ignorábamos todo aquello que estaba pasando allí, porque nuestra mirada iba más hacia Europa, hacia Francia e Inglaterra y no sabíamos que existía la Psicología Comunitaria; lo que buscábamos era hacer una Psicología Social que fuera socialmente sensible, que respondiera a los problemas de nuestros países. Así que para mediados de los años 70', en esta parte del continente se había comenzado a hacer algo que ya se llamaba Psicología Comunitaria, pero que con la excepción de Puerto Rico y quizás de una institución jesuita en México, el ITESO ${ }^{1}$ (que tenían más contacto académico con los EE.UU.), que comenzaron usando esa denominación, en países como Venezuela, Brasil, Chile, Colombia, que fueron los primeros en fomentar trabajos con o en comunidades, no se conocía ese nombre.

Lo que si habíamos comprendido, es que la Psicología Social que estábamos trabajando necesitaba ser ampliada. Nos dábamos cuenta de que ésta se producía en un mundo cambiante, 1 Instituto Tecnológico de Estudios Sociales de México en el cual queríamos que ocurrieran cambios que tenían que incorporar muchos factores, mucha gente, muchas técnicas. De allí que la complejidad sea fundamental. En esa situación nos encontrábamos al final de los años 70'.

En 1977 empecé a hacer trabajos con estudiantes de pre-grado, en los cuales comenzamos también a incorporar a las personas con un rol más allá que el de sujeto de investigación. En esa época, me ayudó mucho haber leído un libro que me dio un colega colombiano muy querido, se llamaba Miguel Salas Sánchez, a quien le conté que queríamos trabajar con las personas y las dificultades que teníamos derivadas de las limitaciones de la psicología que conocíamos. En ese trabajo mis alumnos y yo nos dimos cuenta de que, los cuestionarios, las entrevistas, las escalas que se usaban entonces, no nos producían el conocimiento que queríamos, porque al final terminábamos volviendo a elaborar el problema que nos habían planteado.

Eso nos ocurrió en 1976 con una gran investigación que hicimos en nuestro Dpto. de Psicología Social en la Universidad Central de Venezuela (UCV). El Instituto Nacional de Vivienda (INAVI) de mi país, Venezuela, le pidió al Departamento de Psicología Social de mi Universidad que hiciese una investigación sobre por qué las personas que recibían en un sistema de venta muy favorable y accesible, viviendas de interés social: apartamentos o pequeñas casas, que pasado un período relativamente corto (uno o dos años), se encontraban en mal estado. Estas viviendas (casas, edificios) tenían la posibilidad de crecer. Por ejemplo, las llamadas casas en pendiente (construidas en algunos de los cerros que rodean la ciudad de Caracas) tenían cocina, baño, sala-comedor y dos habitaciones, además una terraza que tenía los cimientos para que las personas construyeran según sus necesidades.

Correspondencia: Maritza Montero. Universidad Central de Venezuela (UCV).

Correo Electrónico: mmonteroster@gmail.com. 
Contaban además, con un pequeño jardín que colindaba con otras casas semejantes. El problema del INAVI, era que $80 \%$ del presupuesto de construcción se iba en reparar esas casas y edificios ya entregados a sus propietarios, entonces se preguntaban, ¿qué pasaba con casas y edificios que se entregaban en buen estado y al poco tiempo necesitaban ser reparados?

Nosotros encontramos que al final de la investigación, lo que habíamos hecho era redefinir el problema, pero no estábamos encontrando las verdaderas soluciones. Cada uno de nosotros, en el Departamento, estaba muy entusiasmado porque nos habían encargado una tarea importante, pero lo que produjimos fueron hipótesis, que eran nuestras, muy intelectuales si, pero esas hipótesis no las habíamos compartido con nadie que estaba en la situación, no las habíamos compartido con la gente involucrada.

A partir de una observación no participante, en los diversos lugares donde estaban esas urbanizaciones (cerros y también terrenos planos), advertimos que había ciertos núcleos de apartamentos donde no había deterioro en absoluto; mientras que otros estaban deterioradísimos y ¿cuánto tiempo hacía que se habían construido?, aproximadamente dos años. Se encontraban dañadas sobre todo las escaleras, los ascensores -algunos ya no servían- así como las entradas de los edificios y los jardines, que se habían convertido en estacionamiento, cuando inicialmente se los había diseñado para que los niños tuvieran un espacio donde jugar.

La primera hipótesis que nos planteamos fue que "los edificios habían sido mal construidos", responsabilizando de esta manera al Estado.

Otra hipótesis, fue que se había llegado a esta situación por "un problema de agresividad adolescente o debido a la conducta de personas desviadas", en esta hipótesis, las causas de los problemas recaían en las personas. Otros pensaron en problemas de salud.

Efectivamente se vio que algunas personas lanzaban basura desde los pisos más altos de algunos edificios; que los ascensores se averiaban porque las personas que estaban en los primeros pisos como no los usaban, no pagaban los correspondientes gastos de condominio; y las zonas comunes, estaban degradadas, nadie las cuidaba. Cuando nos decidimos a tocar las puertas y visitar los apartamentos, vimos que algunos tenían alfombras de pared a pared y en general estaban muy limpios y bien mantenidos. Los habitantes entendían la propiedad de la puerta de la casa para adentro, la propiedad común no se entendía un deber común.

En ese momento me dí cuenta de que lo que estábamos haciendo no servía. Mi hipótesis inicial era que "las personas no tenían un concepto de propiedad debido al tipo de instrumento legal", ya que la persona no podía vender el apartamento si no lo había pagado completamente. Si lo quería vender antes, lo tenía que devolver al INAVI, obteniendo a cambio buena parte del dinero invertido. La imposibilidad de poder venderlo irrestrictamente, me llevó a pensar que era una forma de propiedad restringida, y que por allí podíamos encontrar una posible causa del problema. Creo que todos hicimos muy bien un trabajo equivocado.

Luego pensando y discutiendo con otros colegas y estudiantes, decidimos que la gente tenía que participar, que la gente debía ser oída, que la gente debía opinar, pero no en cuestionarios con preguntas previamente establecidas, sino de manera más libre. El trabajo que habíamos hecho hasta el momento con la gente, había sido preguntar cosas establecidas, entonces a partir de esta nueva participación, empezamos a trabajar con ellos y vimos que el problema era mucho más complejo. Que la gente debía participar.

La otra idea básica es la idea de la justicia social, que está en la base de todos los programas de Psicología Comunitaria que conozco y que aparecen en los primeros textos tanto en Estados Unidos, como en América Latina y en Europa, más tarde.

En ese sentido hay dos aspectos a señalar:

\section{- la episteme de la relación y}

- la episteme de la otredad.

Ambos conceptos son productos latinoamericanos, vienen de la Filosofía de la Liberación. Detrás de esta filosofía, está la influencia de un gran filósofo: Emmanuel Lévinas (ver su obra Totalidad e infinito, 1997), quien escribe sobre el otro e introduce la idea de la episteme del egoísmo, de la individualidad. Lo que plantea la filosofía de la liberación que nace y crece en América Latina, sobre todo con Enrique Dussel, (nacido en Córdoba, Argentina y radicado en México), es que se necesita partir de la relación, porque todos somos, como decía Freire, "seres de relaciones en un mundo de relaciones" (Freire, 1970). Dussel $(1987,1998)$ 
propone una modificación de la totalidad dialéctica hegeliana (Hegel) y marxista (Marx), que se reduce a 3 elementos básicos: tesis, antítesis y síntesis, en la cual lo distinto, lo desconocido, pero existente, no tiene cabida. Razón por la cual la dialéctica hegeliana debe expandirse, ensancharse, para que el Otro desconocido pueda entrar en esa totalidad.

Lo que plantea Dussel y también Alejandro Moreno $(1993,2004)$-Psicólogo que ha trabajado desde la perspectiva psicosocial esta idea-, son los conceptos de episteme de la relación y episteme de la otredad, que reconocen el pensamiento de un Otro cuya presencia no es reconocida en esa totalidad. Esas epistemes, en la psicología comunitaria, se muestran en la presencia y referencia de la gente que encontramos en las comunidades. En América Latina muchas psicólogas y psicólogos trabajamos con personas en situación de pobreza, Esa es una elección, pues se puede trabajar comunitariamente en muy diferentes tipos de comunidades, pero hemos elegido las situaciones de pobreza porque, las desigualdades sociales son fuentes de problemas fundamentales en nuestros países. Y por eso la psicología comunitaria que hemos construido busca, no paliar los problemas, sino transformar a las personas que los sufren, en procesos compartidos, participativos y comprometidos en los cuales todos tengan voz y acción. Todos en la misma totalidad ana-dialéctica.

¿Cómo tenemos educación excelente para ciertos grupos sociales, y educación infame para otros grupos sociales?, supongo que en Uruguay no es así, pero en mi país lo es, también en otros países latinoamericanos. Un niño de clase media o de clase media alta, tiene muy buena educación, si es de la clase más elevada tendrá la mejor educación del mundo, tiene todo a la mano. Mientras que las escuelas de la mayor parte de la población de esos países tienen en aulas que no dan abasto a niños y niñas aglomerados, con una pobre educación.

Entonces la idea que alimenta la episteme de la relación es la apertura hacia un otro, un nuevo elemento desconocido, no pensado, no imaginado, pero con el cual vamos a encontrarnos, que es totalmente diferente pero que puede entrar en esa totalidad; que tiene ideas, que tiene conocimientos distintos, que tiene preguntas o algún problema que va a influir en esa totalidad, abrir la totalidad, expandir la totalidad al Otro.
Eso se complementa con la episteme de la otredad, que supone el carácter activo de las personas, como se ha entendido en la psicología comunitaria creada en algunos países de América Latina. Nadie espera que lo inviten a integrar la totalidad, estamos allí de una manera u otra en la vida social, e irrumpimos si podemos, si nos dejan. E inclusive si no nos dejan, en algún momento vamos a irrumpir con un determinado modo de conocer. Se reconoce además, el carácter histórico que tienen las comunidades, así como la inclusión en la comunidad y de la comunidad, en otras relaciones sociales.

El poder simétrico es otra producción psicológico-comunitaria en proceso de desarrollo en algunos de nuestros países. Parece una contradicción ¿cómo es posible que el poder sea asimétrico? Lo que ocurre es que estamos acostumbradas/os a la idea de poder que viene de Max Weber y mucho antes, de Hobbes, por ejemplo. La concepción del poder que hemos usado en América Latina y en todo el mundo, ha sido canonizada por Weber (1925) y consiste en lograr que las personas hagan aquello que nosotros queremos que hagan, esa es la definición que encontramos en Fischer (1992) y en tantos autores que han trabajado el poder, tanto en la Psicología como en la Sociología.

Hay una clasificación de dos autores estadounidenses (French y Raven, 1959) que dice que hay seis clases de poder, desde el poder coercitivo, hasta el poder legítimo, pues no todos los poderes son autoritarios. Hay un poder que viene a través del cariño, por ejemplo el uso del cariño en la familia, de los hijos, del marido, que permite poder conseguir que los otros hagan cosas. Alguna vez lo hemos practicado y los niños lo hacen con nosotros: "¿mamá tu me quieres?", “¿sí?, entonces dame más dinero para la merienda", etc, etc. Si tu me quieres pruébalo de esa manera. Esto indica que el poder es multiforme.

La idea de un poder simétrico, aparece publicado en el año 1989, en un pequeño trabajo de Irma Serrano y Gerardo López Sánchez (1986), muy escueto todavía, pues era una primera aproximación al tema. En 1991 escuché la conferencia que dio Irma Serrano-García en Costa Rica, sobre ese tema y quedé deslumbrada, porque hablaba de la posibilidad de que el poder fuera asimétrico y no porque sean comparables las fuerzas con las que se trabaja. 


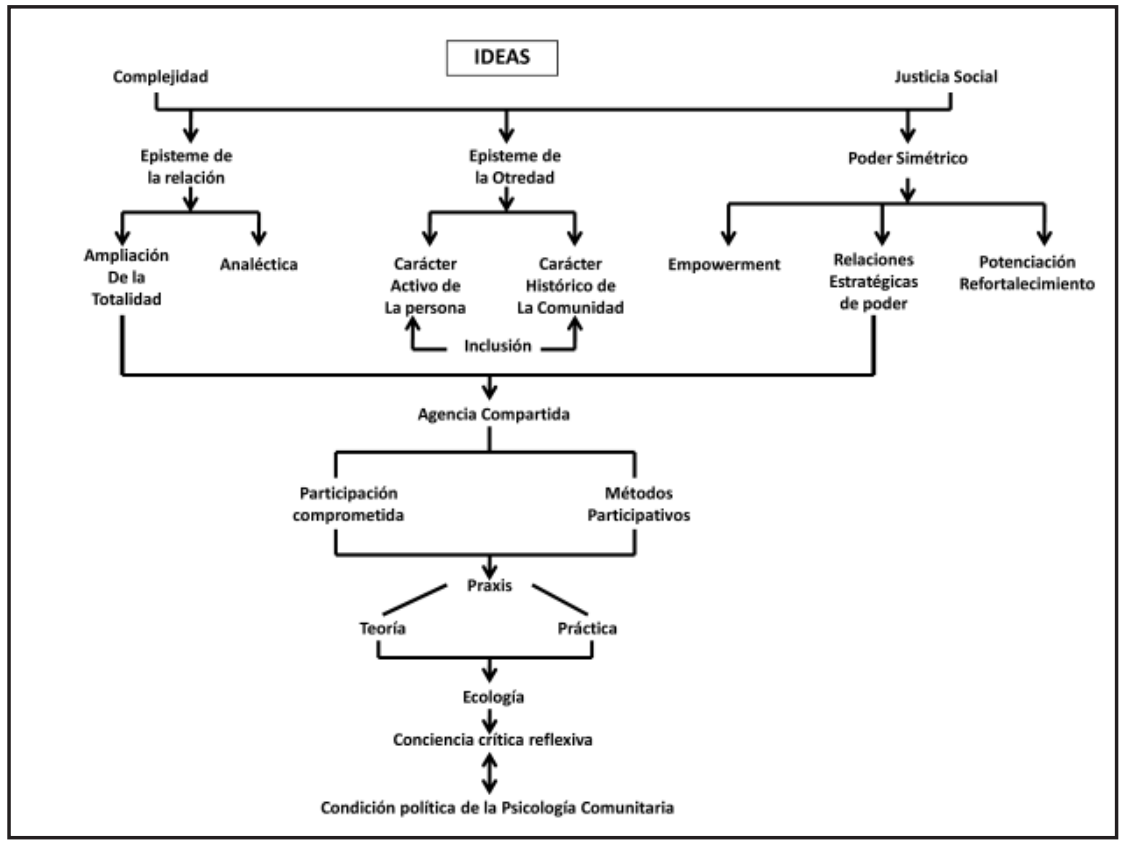

Ideas principales en la psicología comunitaria. Montero, M. 2010.

Por ejemplo, Carlos Slim es el hombre más rico del mundo, no podemos competir con él en fortuna, pero la idea es que si bien los recursos son diferentes (entre Slim y cualquiera de nosotros), toda persona tiene poder, todos tenemos algún poder, justamente por aquella idea de la pluralidad de los poderes de la que ya hablaba la Psicología. Esa pluralidad nos permite tener recursos diferenciales. En muchos casos no podemos competir con los mismos recursos; por ejemplo, quien dirige la policía tiene un cuerpo armado a sus órdenes; los y las ciudadanos/as tenemos otros recursos, que se pueden contraponer de tal manera que sea necesario que otras personas, que poseen algo que deseamos, se interese y podamos llegar a un intercambio beneficioso para ambas partes. Pero sobre todo, saber que todos tenemos poder es una idea muy necesaria en nuestros países, marcados por la minusvalía frente a políticas y creencias negativas.

En la situación de poder asimétrico siempre hay alguien (persona $A$ ) que controla los recursos y por lo tanto impone las normas, y hay una persona $B$ que tiene que obedecer esas normas, pero aspira a los mismos recursos y también quiere y necesita participar.

En la situación simétrica de poder, A tiene recursos, $B$ tiene recursos también, que son diferentes, y A se interesa en los recursos de $B$ porque pueden ser necesarios, deseables 0 peligrosos y debe haber una negociación (con estrategias de poder) y también incertidumbre, aunque no necesariamente siempre es feliz esa solución. Pero es importante saber que se tiene poder y que eso nos llevará a lograr normas, o situaciones o acciones logradas por ambas partes. O a la reivindicación de derechos que nos corresponden.

Hay un punto intermedio que no se ha tomado suficientemente en cuenta, entre esta concepción que nace de la Psicología Comunitaria. De hecho el trabajo de Irma Serrano y Gerardo López Sánchez está incluido en el primer libro que publiqué en Psicología Comunitaria, editado por la Universidad de Guadalajara -ya agotadocuya primera edición fue en 1994 (se hizo una segunda edición en 2001) y ya no está porque no existe más la editorial de la Universidad de Guadalajara. El trabajo de Serrano y López Sánchez, es interesante por la propuesta, ellos describen de dónde salió el modelo, de un trabajo práctico realizado con una comunidad en Puerto Rico.

En Estados Unidos, la relación de poder en la Psicología Comunitaria, se trabaja a partir de una noción introducida por Julian Rappaport, en 1981. Para mi, el psicólogo comunitario estadounidense más interesante. Él introdujo la noción de empowerment-aunque no es el quien crea ese neologismo- cuya traducción castellana es empoderamiento (expresión que no soporto). Rappaport tomó el término de dos sociólogos (Berger y Neuhaus) y la introduce en una 
conferencia publicada en 1981, en la Revista de la American Psychology Association (APA), The American Psychologist. Ese concepto se extendió muy rápido en la Psicología Comunitaria. Pero ya en 1993, Stephanie Rieger, critica la noción, señalando que supone que alguien tenga el poder de dar el poder. Los psicólogos y psicólogas no somos dioses y nadie podría hacer eso (incluido Rappaport), pero si tratamos, queremos, fortalecer. Por eso prefiero usar la palabra fortalecimiento, empleada desde los inicios de la psicología comunitaria en nuestros países. La gente tiene alguna fuerza y hay que fortalecer las capacidades que tiene la gente, hay una diferencia muy grande entre "empowerimg someone" (darle poder a un alguien) y fortalecer a ese alguien. Además no es un proceso definitivo, Siempre es una cosa acotada, porque se puede fortalecer para algo, no para todo a la vez. La persona puede seguir no fortalecida, sentirse impotente o débil respecto de otras cosas; nunca cubrimos todo y eso debemos tenerlo en cuenta. Debemos ser más modestos, sensatos y cuidadosos en esto. Además, Riger (1993) decía que no se toma en cuenta la situación, hay situaciones en que no es posible aplicar lo que se estaba planteando como técnicas de empowerment.

Es interesante ver que a mediados de los años 90' Rappaport enriquece el trabajo con el empowerment, usando narrativas, eso es algo muy interesante, que también se ha hecho en América Latina desde hace mucho tiempo. Primero lo hicieron los antropólogos y los sociólogos, hay incluso autobiografías o sea gente que narra su propia vida, que se usaban como técnicas de trabajo social y sociológico. Podemos encontrarlas en Costa Rica, Venezuela, Colombia, yo creo que también en otros países, esa es una técnica que ha estado en muchos países latinoamericanos, y con la cual se hacen trabajos muy interesantes.

Volviendo al tema del poder, en la estrategia, en las relaciones de poder, algo que todos están usando es la agencia compartida ¿qué es?. Se trata de diversos agentes compartiendo una misma intención. Una cosa es decirlo y otra es hacerlo, el reto más importante que estoy viendo en la Psicología Comunitaria en este momento, es la unión entre los agentes externos que vienen del Estado, de las ONGs, de las iglesias, toda la gente que trabaja con las comunidades $\mathrm{y}$, los agentes internos, que son las personas organizadas dentro de una comunidad, los informantes claves o los líderes de la comunidad. Es muy difícil, hay casos en que el Estado dice, por ejemplo, que hay que hacer una carretera y que es necesaria, pero destruye un lugar porque no han averiguado entre la gente, la función que cumple esa calle o lugar para ellos. Quizás allí había una plaza donde la gente se reunía que es destruida con la construcción de la carretera, o un camposanto, donde reposan los restos de sus antepasados, Lugares sagrados, lugares de encuentro que cumplen una función fundamental para la comunidad. Esto sucede en muchos países, no sólo en los nuestros.

Esa agencia compartida es uno de los puntos álgidos en estos momentos, porque refiere a cómo las(los psicólogos/as hablamos de concientizar, desde la idea freiriana y la hemos denominado como métodos para la conciencia. Pero no es suficiente el concientizar a las comunidades, también es necesario concientizar a los funcionarios públicos, a los propios psicólogos que van a las comunidades, a todos los agentes externos, para producir la participación comprometida, el compromiso participativo que son ya una unidad binomial. Toda la participación que tenemos tiene que tener un compromiso y los compromisos son diferentes, y eso hay que respetarlo. Hay gente que dice "yo solo puedo hacer tales cosas", y las hace muy bien y son necesarias. Hay otras personas que todo el día trabajan por la comunidad y que se cansan. Conocí un líder, que decía "lo único que yo no hago aquí es dormir", pero estaba perdiendo a su familia. Los lideres deben rotar, deben tener el tiempo para dormir, para soñar, porque también hay un peligro, nadie ama tanto la comunidad como un líder narcisista positivo, es decir, aquel que cree que: "yo soy el que mas los ama", por lo tanto sólo lo que él dice es lo que se puede hacer. $Y$ con los agentes externos ocurren muchos desaciertos por falta de conciencia y entendimiento de lo que deben hacer.

Los métodos participativos, son también de origen latinoamericano. La investigaciónacción participativa, es un producto latinoamericano, inspirado en la investigación-acción que esbozó en su último artículo Kurt Lewin, publicado en el № 6 del Journal of Social Issues. Luego un libro titulado Resolving Social Conflicts (Resolución de problemas sociales) recolectó los últimos trabajos de Lewin y allí 
también presenta el artículo en el cual esbozó la investigación-acción (action research). Su propuesta es un movimiento de vaivén, donde el investigador/a trabaja en su oficina y luego va y recoge datos, los procesa inmediatamente y, hace correcciones y vuelve al campo y así sucesivamente. Lewin consideraba que se pierde mucho tiempo entre el momento en que se recolectan y se procesan los datos y la respuesta que se da a la población. Algo de esto nos pasa a los profesores universitarios, hay que modificar el programa, pues los alumnos están descontentos con el programa, les parece que algo falta; entonces trabajamos sobre eso y los beneficiarios serán los de la clase siguiente, que no habían hecho los reclamos. Damos los resultados a otros, tendríamos que tener la posibilidad de hacer los cambios en el momento, aunque es muy difícil, muy difícil, pues una serie de normas nos lo impide. Eso pasa con el "Action research", que tuvo un gran impacto, fue desarrollado en el mundo anglosajón después de la muerte de Lewin, sin embargo no fue tan usado por las ciencias sociales, sino mas bien por el campo de la ciencia de la comunicación, claro que también es social por supuesto, pero fue donde primero se usó y eso es muy interesante, como pasó con los grupos, por ejemplo los grupos focales (Merton, Fiske y Kendall, 1956), que fueron tomados por el campo del mercadeo y la propaganda, antes de que los utilizaran el resto de las ciencias sociales.

Todo esto tiene que ver con la praxis, es decir, un modo de producir conocimiento, en el cual se produce teoría que genera práctica y práctica que genera teoría. Lo cual está claro en la Psicología Comunitaria. A finales de los años 80, algunos colegas decían que esta era una Psicología que no tenía teoría, en la que no se veía la teoría, ¿porqué?, porque se estaba construyendo y venimos de una práctica donde no solemos esperar que se genere teoría, pero todo lo que hacemos, sea pensar en un poder simétrico, o en la investigación, o en la participación, es tanto un problema teórico como también práctico. Por ejemplo, trabajar la conciencia, tenemos una gran teoría que viene de Paulo Freire (1970), de la fenomenología; pero se convierte en un método y se convierte en una teoría pensada en otros términos al usarla en la práctica. Tomamos los conceptos freirianos de liberación, de concientización, de desalienación, de desideologización (están todos en Freire), cómo los usamos, cuándo los usamos tenemos ya que modificar cosas. Entonces estamos haciendo práctica y pequeñas contribuciones teóricas y, cuando nos ponemos a pensar en ello, encontramos que se ha venido formando una teoría. Las epistemes son un aspecto que indican teoría y vienen de la praxis.

Otra idea de ese tipo es la de ecología, que viene de Norteamérica, de James Kelly, que introduce una visión ecológica o sea del equilibrio de la sociedad con la naturaleza y los seres humanos entre si. Es la idea de crear un sistema social ecológico. Otra idea básica en la psicología comunitaria es la de crítica reflexiva que debe haber en toda comunidad y que si no la introducimos los y las psicólogas, la va a introducir la propia comunidad. Esa idea se relaciona con la práctica simétrica del poder, pues cuando cualquier persona de la comunidad puede decir, "esto no me convence", "tal cosa no me parece", "nosotros no podríamos hacerlo", o "lo haremos de otro modo", se hace crítica y se ejerce el poder de opinar y discutir, para decidir.

Algo que he trabajado bastante, porque es evidente, es el carácter político de la Psicología Comunitaria, que a su vez necesita de la conciencia. ¿En qué sentido?: si trabajamos conciencia, si trabajamos equilibrios y poderes, participación y compromiso para transformar, eso es político; ese es el verdadero sentido de las políticas. Es la ocupación del espacio público a través de la acción de las comunidades, es conocer los derechos y deberes que tenemos, y eso es la política; no es cosa de partidos políticos aunque ellos se han auto-otorgado ese privilegio; es cosa de todo nosotros, de todos los ciudadanos que somos responsables y tenemos que ejercer esa responsabilidad y tenemos deberes, derechos. Eso es fundamental para el trabajo comunitario, porque la gente dice, "es que no nosotros no podemos" una idea de minusvaloración que erradica la conciencia. Era Martín Baró quien decía que cuando él daba sus homilías, que eran políticas esencialmente, la gente le decía "uno de pobre no puede" y ese es el trabajo de fortalecimiento que hay que hacer, para que se sepa que por ser pobre no se deja de poder.

Entonces, el desafío en los programas educativos, para formar en esta disciplina, está en permitir la participación. He visto programas, sumamente cerrados, con la práctica separada de la enseñanza. No puede enseñarse Psicología Comunitaria, propiamente dicha, si no hay una 
práctica al mismo tiempo, porque no es una asignatura exclusivamente teórica, tiene que haber una práctica. Y la teoría se aprende aplicando y corrigiendo en la práctica.

La idea de usar la problematización (Montero, $2007,2009)$ como un método para la concientización se produjo en mi práctica, a partir del cómo hacer preguntas problematizadoras, pues no sirve de nada el cantar una cartilla. Tenemos que ser flexibles, en el sentido de tener claros los objetivos, pero haciendo que los modos de llegar al objetivo sean compartidos con la comunidad, ella puede tiene sus objetivos y tenemos que negociar, si podemos nosotros admitirlos, ya que hay una cuestión ética aquí también, hay cosas que no podemos hacer y que no debemos hacer. Eso debemos decirlo de entrada, porque tiene que quedar claro; así como debe haber esa unión entre teoría y práctica con la posibilidad de que la persona reciba, no sólo un conocimiento que viene -si son estudiantes-, de los libros y de las revistas. Todo tiene que ver con cómo eso funciona en la práctica, para poder improvisar y adaptarse a cosas inesperadas, analécticas, que vienen de la práctica.

Por ejemplo, en el primer trabajo con una comunidad, que fue un trabajo pedido por esa comunidad, ya que sus líderes fueron a pedir ayuda a un Departamento del entonces Ministerio de la Familia, que tenía un Programa de Educación Comunitaria.; ellos pedían ayuda para hacer una serie de cosas. Quién dirigía ese Departamento, había sido alumno mío, y me llamó a ver si nosotros podíamos ocuparnos porque ellos tenían muchísimo trabajo y no tenían suficientes recursos. A mi me pareció que era una excelente oportunidad de hacer que los y las alumnas de mi curso pusieran en práctica sus conocimientos (lo que además era parte del programa). Primero fui yo a conocer la comunidad, a hablar con ellos y cuando empezamos tuvimos que poner los límites, en el sentido que hay cosas que no podemos hacer y si estamos en la academia, tenemos ciertos límites, uno de ellos es el tiempo académico: la duración de un semestre. Cuando expliqué eso me dijeron, "así no sirve", pero era la única manera en que podíamos hacerlo. Entonces dije: "podemos trabajar hasta $x$ fecha y nos comprometemos a hacer el trabajo" (una evaluación de necesidades y recursos que incluía un censo de la población destinado a diversos fines comunitarios) ... "yo puedo seguir viniendo pero los alumnos después estarán presentando sus exámenes y luego se cierra la Universidad. Si algunos quieren venir en vacaciones con mi supervisión, es un asunto de ellos, y si no pueden, también es su derecho irse de vacaciones." Las personas de la comunidad lo entendieron y aceptaron.

Nos pidieron una cosa muy concreta, ellos eran una comunidad bastante organizada con un centro de salud, pero las personas habían decidido ocuparse ellos de la vacunación porque los vacunadores no cumplían bien sus funciones, no les gustaba subir al cerro por las escaleras que son sucias, poco seguras, tienen su dificultad y bajar es peor, cuando no se está acostumbrado. Entonces quedaba sin vacunar la mitad de un barrio que a la vez eran los más pobres, porque son los que viven más arriba. La comunidad necesitaba saber cuántas vacunas pedir, eso es lo que nos pedían, además de adiestrarse en la aplicación de las mismas, ya que serían ellos los vacunadores. Había que hacer el censo, se calculaba que había entre veinticuatro mil y veinticinco mil personas allí, ni siquiera los cuatro meses que pensábamos estar allí nos iban a alcanzar, pero había una manera de hacer este censo extrapolando, tomando una muestra representativa, para eso pedimos un mapa aéreo en la oficina de cartografía del Estado.

Con la gente de la comunidad porque no podríamos haberlo hecho solos y nos habríamos equivocado, pudimos hacerlo. Esa comunidad tiene una sola calle que va en subida y de ella salen radios con escaleras y veredas. Primero pensamos marcar a partir de las veredas y ellos nos dijeron que no, que así no, porque ellos sabían cómo eran las secciones, "de aquí hasta acá y hasta este punto viven los XXX", y "de acá para acá están los YYY" " “de aquí para acá están los orientales" (los del oriente de la república)", y esa era la distribución adecuada, de lo contrario, no hubiéramos tenido una representación verdadera. Luego ellos contribuyeron a recolectar los datos, tenía sólo trece estudiantes, no daba para hacer todo eso y pensábamos que tardaríamos dos días trabajando de nueve a tres de la tarde, sábado y domingo.

Lo que había pensado que duraría dos días, finalmente se hizo en una sola mañana. Las preguntas las discutimos con la gente, se las explicamos, se encantaron con el método y se les ocurrió hacer todas las preguntas del mundo y tuve que explicarles que no se puede hacer todas esas preguntas, pues tardaríamos mucho tiempo con cada persona y la aburriríamos. Debían ser no más de 30 preguntas. Ellos estaban 
ávidos de saber cosas, también querían saber la cantidad de desempleados que había. Al final hicimos un acuerdo y quedaron 34 preguntas. Le dijimos que ellos podían volver a hacer esto, si les interesaba, con esta misma muestra, Les explicamos cómo hacer la elección de las casas $o$ de las personas. $Y$ terminamos celebrando con una comida.

No debemos creer que "lo que hay que hacer en la comunidad es esto, esto y esto" según lo dice algún canon, esto es justamente lo que no debemos hacer, es verdad que tenemos unos métodos, una teoría, unos conceptos, pero tenemos que escuchar lo que dice la comunidad y eso es necesario que se sepa.

Creo que la complejidad, la justicia social, la participación-compromiso, la conciencia y el poder de la comunidad, aunque someramente, se han descrito en esta charla.

\section{REFERENCIAS}

Dussel, E. (1977/1988) Introducción a la filosofía de la liberación latinoamericana. Bogotá: Nueva América.

Dussel, E. (1987) Accesos hacia una filosofía de la liberación. Buenos Aires: La Aurora.

Dussel, E. (1998) La ética de la liberación. México: UNAM.

Fals Borda, O. (1959) Acción comunal en una vereda colombiana. Bogotá, Colombia: Universidad Nacional, Monografías Sociológicas.

Fals Borda, O. (1978). Por la praxis. Como intervenir en la realidad para transformarla. En Crítica y Política en Ciencias Sociales. El debate. Teoría y práctica. (209272). Bogotá, Colombia: Punta de Lanza.

Fals Borda, O. (1985) Conocimiento y poder popular. Bogotá, Colombia: Siglo XXI.

Freire, P. (1970) Pedagogía del oprimido. Montevideo, Uruguay: Tierra Nueva.

Fischer,G. N. (1992) La dynamique du social. Violence, pouvoir, changement, Paris: Dunod.

French, J. y Raven, B. (1959) The bases of social power. En D. Cartwright (Ed.) Studies in social power (118-149). Ann Arbor: Institute for social research.

Lévinas, Emmanuel (1997). Totalidad e infinito: ensayo sobre la exterioridad. España: Sígueme.
López-Sánchez, G. \& Serrano-García, I. (1986) El poder: posesión, capacidad o relación. Revista de Ciencias Sociales, Vol. XXV (1-2) 121-148.

Merton, R. K. , Fiske, M. y Kendall, P. L. (1956) The Focused interview. New York: The Free Press.

Montero, M. (1991). Concientización, Conversión y desideologización en el trabajo psicosocial comunitario. Boletín de la AVEPSO. XIV (1) 3-12.

Montero, M. (1998b) Psychosocial community work as an alternative mode of political action (The construction and critical transformation of society). Community, Work and Family, 1 (1), 65-78.

Montero, M. (2000a) Participation in participatory action research. Annual Review of Critical Psychology , 2, 131-144.

Montero, M. (2001) From action and reflection to critical psychology. International Journal of Critical Psychology , 2, 84-89.

Montero, M. (2010).Crítica, autocrítica y construcción de teoría en la psicología social latinoamericana. Revista Colombiana de Psicología, 19 (2).

Montero, M. (2003) Teoría y práctica de la psicología comunitaria. La tensión entre comunidad y sociedad. Buenos Aires, Argentina: Paidós.

Montero, M. (2004a) Relatedness as the basis for liberation. International Journal of Critical Psychology, 9. 61-74.

Montero, M. (2004c) Introducción a la Psicología Comunitaria. Conceptos y procesos. Buenos Aires, Argentina: Paidós.

Montero, M. (2006) Hacerparatransformar. BuenosAires: Paidós.

Montero, M. (2007) La problematización como aspecto crítico en el proceso de liberación. En I. Dobles, S. Baltodano y V. Leandro (Comps.) Psicología de la liberación en el contexto de la globalización neoliberal (216-229). San José de Costa Rica,: Universidad de Costa Rica.

Montero, M. (2009) Methods for liberation: Critical consciousness in action. En M. Montero y C. Sonn (Eds.) Psychology of liberation (73-92). New York: Springer.

Moreno, A. (1993) El aro y la trama.Episteme, modernidad y pueblo. Caracas, Venezuela:CIP.

Rappaport, J. (1981) In praise of paradox: A social policy of empowerment ober prevention. American Journal of Community Psychology 9 (1) 1-25.

Riger, S. (1993) What's wrong with empowerment. American Journal of Community Psychology, 21(3) 279-292.

Serrano-García, I. y López Sánchez, G. (1994) Una perspectiva diferente del poder y el cambio social para la psicología Comunitaria. En M. Montero (Coord.) Psicología Social Comunitaria (167-210). Guadalajara, México: Universidad de Guadalajara.

Weber, M. (1925/1964) Economía y sociedad. México, FCE.

\footnotetext{
i (N de la Ed). La Prof. Dra. Maritza Montero es una conocida académica que desarrolla proyectos en comunidad, a la vez que forma recursos expertos a nivel universitario en Psicología Comunitaria en su Universidad (UCV) y como profesora invitada en muchas Universidades de todo el mundo. Esta presentación recoge la exposición -en forma coloquial- de la Prof. Montero ofrecida en la Facultad de Psicología de la Universidad Católica del Uruguay, en el marco del programa del Postgrado de Especialización en Intervención Psicosocial, en el año 2011; revisada por la autora.
}

Para citar este artículo:
Montero, M. (2011). Nuevas perspectivas en Psicología Comunitaria y Psicología Social Crítica. Ciencias
Psicológicas V (1): 61-68.

